\title{
Concentração de Nitrogênio Uréico Plasmático (NUP) e Produção de Leite de Vacas Mestiças Mantidas em Gramíneas Tropicais sob Pastejo Rotacionado 1

\author{
Maria Lúcia Pereira Lima ${ }^{2}$, Telma Teresinha Berchielli ${ }^{3}$, Paulo Roberto Leme ${ }^{4}$, José Ramos \\ Nogueira², Maria da Graça Pinheiro²
}

\begin{abstract}
RESUMO - O trabalho foi realizado com o objetivo de estudar os níveis de nitrogênio uréico plasmático (NUP) de vacas mestiças leiteiras mantidas em duas áreas de pastejo rotacionado, uma de capim-elefante cv. Guaçu (Pennisetum purpureum Schum. cv. Guaçu) e outra de capim-Tanzânia (Panicum maximum Jacq. cv. Tanzânia). Foram avaliadas a produção de forragem e as frações colmo, folha e material morto, com base na matéria seca (MS), bem como os teores de proteína bruta (PB) e fibra em detergente neutro (FDN) nas amostras de forragem. O sangue foi coletado em quatro épocas, utilizando-se 16 vacas por espécie de capim. A média da massa de forragem pré-pastejo foi de 5.321 e $5.384 \mathrm{~kg}$ de MS/ha por ciclo de pastejo para o capim-elefante e capim-Tanzânia, respectivamente. A forragem desaparecida pós-pastejo, referente à folha, ao colmo e ao material morto foi de 1.400, 620 e $443 \mathrm{~kg} \mathrm{de} \mathrm{MS/ha} \mathrm{para} \mathrm{o} \mathrm{capim-}$ elefante e de 1.586, 736 e $132 \mathrm{~kg}$ de MS/ha para o capim-Tanzânia, por ciclo de pastejo. As médias de quatro ciclos de pastejo de PB e FDN nas amostras da planta inteira, colmo, folha, material morto e resíduo foram de 8,$4 ; 78,5 ; 6,9 ; 77,1 ; 12,5 ; 76,3 ; 5,3 ; 82,6$; 6,$5 ; 80,2$, respectivamente, para o capim-elefante, e de 9,$3 ; 81,6 ; 7,4 ; 82,4 ; 14,3 ; 80,4 ; 6,3 ; 82,9 ; 7,6 ; 81,6$, respectivamente, para o capim-Tanzânia. Foi encontrada diferença significativa nos níveis de NUP das vacas alimentadas nas diferentes espécies de capim e por época de amostragem do sangue. As médias de NUP foram $9,8 \mathrm{mg} / \mathrm{dL}$ para as vacas mantidas no capim-elefante e $10,6 \mathrm{mg} / \mathrm{dL}$ para as vacas mantidas no capim-Tanzânia. Os baixos níveis de NUP encontrados refletem a baixa ingestão de proteína bruta por vacas manejadas em pastagens tropicais.
\end{abstract}

Palavras-chave: fibra em detergente neutro, Panicum maximum Jacq. cv. Tanzânia, Pennisetum purpureum Schum., proteína bruta

\section{Plasma Urea Nitrogen (PUN) Level and Milk Production of Crossbred Cows Kept in Tropical Pasture under Rotational Grazing}

\begin{abstract}
The experiment was performed to evaluate plasma urea nitrogen (PUN) level of crossbred cows under two rotational grazing areas, one of elephantgrass cv. Guaçu (Pennisetum purpureum Schum. cv. Guaçu) and other one of Tanzaniagrass (Panicum maximum Jacq. cv. Tanzania). Forage production, stem, leaf and dead material were also evaluated, on dry matter basis (DM), as well as the crude protein (CP) and neutral detergent fiber (NDF) in the forage samples. Blood was collected four times, using 16 cows for grass species. The average of pre grazing forage mass was 5321 and $5384 \mathrm{~kg}$ of DM/ha by grazing cycles for elephantgrass and Tanzaniagrass. The forage disappeared after grazing, as leaf, stem and dead material was 1400, 620 and $443 \mathrm{~kg}$ of DM/ha for elephantgrass and 1586, 736 and $132 \mathrm{~kg}$ of DM/ha for Tanzaniagrass, by grazing cycle. The averages of CP and NDF in the forage samples during four grazing cycles in the stem, leaf, dead material and residue were 8.4, 78.5, 6.9, 77.1, 12.5, 76.3, 5.3, 82.6, 6.5, 80.2, respectively, for elephantgrass and 9.3, 81.6, 7.4, 82.4, 14.3, 80.4, 6.3, 82.9, 7.6, 81.6, respectively, for Tanzaniagrass. Significant difference was observed for PUN levels of cows fed different grass species and for time of sampling of the blood. The averages of PUN were $9.8 \mathrm{mg} / \mathrm{dL}$ for the cows grazing elephantgrass and $10.6 \mathrm{mg} / \mathrm{dL}$ for the cows grazing Tanzaniagrass. The low levels of PUN reflect low level of crude protein ingestion, for cows grazing tropical pastures.
\end{abstract}

Key Words: crude protein, neutral detergent fiber, Panicum maximum Jacq. cv. Tanzania, Pennisetum purpureum Schum.

\footnotetext{
1 Parte da tese de Doutorado do primeiro autor, parcialmente financiado pela FAPESP.

2 Pesquisador Científico do Instituto de Zootecnia. Av. Bandeirantes, 2419. CEP: 14030-670, Ribeirão Preto, SP E.mail: marialucia@aptaregional.sp.gov.br.

3 Professor da FCAV-UNESP - Jaboticabal, Pesquisador do CNPq. E.mail: ttberchi@fcav.unesp.br

${ }^{4}$ Professor da FZEA-USP - Pirassununga. E.mail: prleme@usp.br
} 


\section{Introdução}

O valor biológico dos alimentos protéicos para vacas lactantes está diretamente relacionado com o estado energético da vaca e o balanço de aminoácidos absorvidos em relação às suas necessidades nutricionais. Nas vacas em lactação, a proteína dietética inclui as frações proteína degradável no rúmen (RDP) e proteína não-degradável no rúmen (RUP). Através da fermentação ruminal da fração RDP é produzida amônia, utilizada na síntese de proteína microbiana. Parte da amônia produzida escapa da incorporação pelos microorganismos, é absorvida e, no fígado, é convertida em uréia. A quantidade de amônia produzida e a que escapa da conversão para uréia refletem diretamente a quantidade de RDP e a disponibilidade de carboidratos passíveis de fermentação para suportar o crescimento dos microorganismos e a síntese protéica. A segunda fonte de uréia é produzida pelo fígado e originária do metabolismo de aminoácidos, incluindo os aminoácidos originários da RUP, da proteína microbiana ou de reservas corporais. Parte desta uréia é reciclada e volta para o rúmen e a outra parte é eliminada através da urina (Butler, 1998).

A concentração de uréia plasmática pode ser usada para monitorar a ingestão de proteína bruta, que deve ser o mais próximo possível das necessidades da vaca, por quatro motivos: o excesso de $\mathrm{N}$ pode prejudicar o desempenho reprodutivo; o excesso de $\mathrm{N}$ aumenta as exigências de energia, uma vez que são necessárias 13,3 kcal de energia digestível para excretar um grama de $\mathrm{N}$; os suplementos protéicos são caros; e a grande quantidade de $\mathrm{N}$ excretada gera impacto ambiental negativo (Broderik \& Clayton, 1997).

Estudos mostraram que vacas leiteiras entre 40 e 100 dias após o parto apresentaram valor médio de $13,4 \mathrm{mg} / \mathrm{dL}$ para nitrogênio uréico do plasma (NUP) (Rowlands et al., 1977). Outros valores foram encontrados para vacas leiteiras com escore corporal e produção de leite distintos, ou seja, média entre 7 e 23,5 mg/dL de NUP (Ruegg et al., 1992; Butler et al., 1996; Broderik \& Clayton, 1997; Butler, 1998; Ruas et al., 2000).

A alimentação com excesso de proteína pode gerar níveis plasmáticos acima de $19 \mathrm{mg} / \mathrm{dL}$ de NUP, interferindo negativamente no desempenho reprodutivo das vacas produtoras de leite (Butler et al., 1996). Hayes et al. (1996) estudaram os níveis de uréia plasmática de vacas com problemas reprodutivos, mantidas em pastagens na Nova Zelândia, com teores de proteína bruta (PB) acima de $20 \%$ e encontram valores de $\mathrm{N}$ da uréia plasmática entre 6,8 e 7,6 mmol/L, correspondente a 19,1 e $21,3 \mathrm{mg} / \mathrm{dL}$ de NUP.

Ruas et al. (2000), trabalhando em condições brasileiras, encontraram níveis de uréia plasmática entre 15 e $33 \mathrm{mg} / \mathrm{dL}$, que corresponde a valores entre 7 e $15 \mathrm{mg} / \mathrm{dL}$ de NUP.

As produções de forragem, assim como a qualidade, variam de acordo com a espécie forrageira e com o manejo adotado. Balsalobre (1996), trabalhando com capim-elefante, encontrou média de $7.978 \mathrm{~kg}$ de MS/ha de massa de forragem inicial em pastejo rotacionado com 45 de descanso e dois dias de ocupação, com adubação de $240 \mathrm{~kg}$ de N/ha $(80 \mathrm{~kg}$ de N/ha após cada pastejo, em um total de três pastejos). Esse autor encontrou relação folha: haste de 0,85. Ribeiro et al. (1999), avaliando o capimelefante anão, encontraram teor médio de PB de 11,3 e $6,8 \%$, nas folhas e nos colmos, respectivamente.

Com relação à produção de massa de forragem inicial em capim-Tanzânia, no período das águas, Cecato et al. (1996) observaram produções de $7.441 \mathrm{~kg}$ de MS/ha, com frequiência de pastejo de 35 dias, enquanto Santos et al. (1999) encontraram produções de $5.772 \mathrm{~kg}$ de MS/ha, com freqüência de pastejo de 38 dias e adubação de $400 \mathrm{~kg}$ de N/ha.

Resultados de produção de leite comprovaram que vacas consumindo capim-elefante, em pastejo rotacionado, podem produzir de 8 a $14 \mathrm{~kg} / \mathrm{dia}$, dependendo do potencial de produção e do estádio de lactação, assim como da lotação utilizada (Lucci et al.,1969; Lucci et al., 1972; Veloso \& Freitas, 1973; Derez \& Mozzer, 1990; Olivo et al., 1992; Fonseca et al., 1998; Cóser et al., 1999; Aroeira et al., 1999). No entanto, publicações sobre produção de leite por vacas mantidas em capim-Tanzânia são raras. Trabalhos realizados no exterior, avaliando o potencial de produção de leite em Panicum maximum mostraram produção de leite entre 9,5 e 10,7 kg/vaca/dia (Davinson et al., 1985a e b).

O presente trabalho foi conduzido com o objetivo de comparar os níveis de NUP, de vacas mestiças em lactação mantidas em pastejo rotacionado de capimelefante cv. Guaçu e capim-Tanzânia, em quatro épocas distintas. Também foram avaliadas a quantidade de matéria seca pré-pastejo e desaparecida pós-pastejo, assim como os teores de PB e a fibra em detergente neutro (FDN) das amostras da massa de forragem inicial, do resíduo e das frações colmo, folha e material morto.

\section{R. Bras. Zootec., v.33, n.6, p.1616-1626, 2004}




\section{Material e Métodos}

O trabalho de pesquisa foi realizado no Núcleo de Pesquisas Zootécnicas de Ribeirão Preto (Estação Experimental de Zootecnia de Ribeirão Preto) do Instituto de Zootecnia, Secretaria de Agricultura e Abastecimento do Estado de São Paulo, no período de janeiro a maio de 2000. A referida fazenda situa-se na latitude sul $21^{\circ} 42^{\prime}$, longitude oeste $47^{\circ} 24^{\prime}$ e altitude de 535 metros.

Foram avaliadas duas forrageiras: o capimelefante cv. Guaçu (Pennisetum purpureum Schum. cv. Guaçu) e o capim-Tanzânia (Panicum maximum Jacq. cv. Tanzânia). A área com capim-elefante era de 7,8 ha e foi subdividida em 21 piquetes, com períodos de ocupação (dois dias) e de descanso (40 dias). Para o capim-Tanzânia, foram utilizados 13,2 ha subdivididos em 12 piquetes com período de ocupação de três dias e período de descanso de 33 dias. Cada área experimental dispunha de cochos com água, cochos com sal mineralizado e árvores agrupadas fornecendo sombra natural. Também havia cochos com água nos corredores e nas proximidades da sala de ordenha.

As adubações foram realizadas aplicando-se $250 \mathrm{~kg} \mathrm{de} \mathrm{N/ha/ano,} \mathrm{subdivididas} \mathrm{em} \mathrm{quatro} \mathrm{aplicações,}$ uma após cada pastejo, utilizando-se o sulfato de amônio, distribuído com adubadora Vicon.

As amostragens para determinação da massa de forragem inicial e residual foram realizadas, respectivamente, antes da entrada dos animais no piquete e após a saída, em quatro piquetes, a cada ciclo de pastejo. Foram colhidas três amostras, ao acaso, a $20 \mathrm{~cm}$ do solo, utilizando-se um quadrado com 2 metros de lado, tanto para o capim-elefante, como para o capim-Tanzânia. Cada amostra foi pesada em balança do tipo dinamômetro da qual foi retirada uma subamostra para separação em colmo, folha e material morto. Uma porção de cada amostra e as subamostras devidamente separadas foram secas em estufa de circulação forçada de ar a $60^{\circ} \mathrm{C}$, por 72 horas, para determinação da ASA (amostra seca ao ar).

A estimativa da forragem desaparecida póspastejo nas frações folha, colmo e material morto, foi calculada subtraindo-se a quantidade presente no resíduo da quantidade presente na massa de forragem inicial.

Foram estudados quatro ciclos de pastejo que tiveram início em 08/12/1999, 23/01/2000, 04/03/2000,
13/04/2000 e 26/12/1999, 30/01/2000, 06/03/2000 e $10 / 2000$ para o primeiro, segundo, terceiro e quarto ciclos de pastejo, nas áreas de capim-elefante e Tanzânia, respectivamente.

Foram utilizadas 16 vacas mestiças (Holandês x Gir) em lactação por pastagem, em quatro épocas distintas que coincidem com os quatro ciclos de pastejo. As vacas foram ordenhadas duas vezes ao dia. A produção de leite foi avaliada no mesmo dia da coleta de sangue (13/01/2000;24/02/2000;06/04/2000 e 25/05/2000). O sangue foi coletado utilizando-se tubos vacuntainer heparinizados, logo após a ordenha da manhã. Imediatamente após a coleta, o sangue foi centrifugado a $4.500 \mathrm{rpm}$, por 15 minutos, e o plasma, congelado em tubos plásticos, a $-18^{\circ} \mathrm{C}$.

As vacas estavam entre a $2^{\underline{a}}$ e $5^{\underline{a}}$ lactação, agrupadas por grau de sangue das raças Holandesa e Gir (1/2, 3/4 e 7/8) e por fase de lactação (de 10 a 90, de 90 a 180 e acima de 180 dias pós-parto), em cada tipo de pastagem.

Os concentrados utilizados tiveram como fonte energética o milho triturado, como fonte protéica o farelo de algodão (42\% de PB) e o farelo de soja (45\% de PB) e ainda um suplemento mineral. A mistura concentrada continha $18 \%$ de $\mathrm{PB}$ e $72 \%$ de NDT. O critério para fornecimento de ração concentrada foi por fase da lactação e o mesmo nos dois tipos de capim. As vacas recém paridas receberam $4 \mathrm{~kg}$ de ração concentrada por dia; vacas entre 90 e 180 dias de parição, $2 \mathrm{~kg}$ de ração concentrada por dia; e vacas com mais de 180 dias pós-parto não receberam ração concentrada.

As amostras de forragem, após determinação da ASA, foram trituradas e encaminhadas para laboratório, para realização da análise da matéria seca (MS) a $105^{\circ} \mathrm{C}$. Nas amostras de massa de forragem inicial (planta inteira), do resíduo e das frações folha, colmo e material morto foram analisados os teores de proteína bruta (PB) e de fibra em detergente neutro (FDN), de acordo com Silva (1990). A estimativa da disponibilidade de PB da folha foi calculada multiplicando-se a PB da folha pela quantidade de folha disponível.

As análises laboratoriais para medir os valores de $\mathrm{N}$ na uréia plasmática foram feitas utilizando-se kit color comercial (Bio Systems Reagents \& Instruments) e as leituras, em espectofotômetro com filtro de $600 \mathrm{~nm}$, segundo Searcy et al. (1967) e Tabacco et al. (1979).

\section{R. Bras. Zootec., v.33, n.6, p.1616-1626, 2004}


Nas análises estatísticas das pastagens, as comparações foram feitas para cada tipo de capim individualmente. Para a análise de variância, foi usada a média das três amostragens feitas por piquete, sendo os ciclos de pastejo a única fonte de variação. As variáveis estudadas foram valores de PB e FDN da planta inteira da massa de forragem inicial, da folha, do colmo e do material morto.

Para uréia plasmática e produção de leite das vacas, foram considerados, na análise de variância, quatro fatores como fonte de variação - três cruzados (tipo de capim, ciclo de pastejo e grau de sangue) e um aninhado (fase de lactação aninhado em grau de sangue). As análises estatísticas foram feitas por intermédio do Proc. GLM do SAS (SAS, 1996).

\section{Resultados e Discussão}

Os resultados encontrados para produção de massa de forragem inicial (pré-pastejo), resíduo (pós- pastejo), proporção de caule, folha e material morto, assim como a taxa de lotação em cada ciclo de pastejo, são observados nas Tabelas 1 e 2, respectivamente, para o capim-elefante e o capimTanzânia. A partir da média geral da massa de forragem pré-pastejo e da lotação, em unidade animal de $450 \mathrm{~kg}$ de peso vivo (UA), estimou-se que imediatamente antes da ocupação do piquete havia disponível $41,67 \mathrm{~kg}$ de MS/UA/dia para o capimelefante e $50,20 \mathrm{~kg}$ de MS/ UA/dia para o capimTanzânia.

Tabela 1 - Médias e coeficiente de variação (CV) da massa de forragem pré-pastejo, resíduo (pós-pastejo), porcentagem de colmo, folha, material morto, relação folha:colmo e taxa de lotação em capim-elefante

Table 1 - Average and coefficient of variation (CV) of pre grazing forage mass, residue (after grazing), percentage of stem, leaf, dead material, leaf:stem ratio and stoking rate in elephantgrass

\begin{tabular}{|c|c|c|c|c|c|c|c|}
\hline & \multicolumn{4}{|c|}{$\begin{array}{l}\text { Ciclos de pastejo } \\
\text { Grazing cycles }\end{array}$} & \multirow[t]{2}{*}{$\begin{array}{l}\text { Média } \\
\text { Average }\end{array}$} & \multirow[t]{2}{*}{$\mathrm{CV}(\%)$} & \multirow[t]{2}{*}{$*$} \\
\hline & 1 & 2 & 3 & 4 & & & \\
\hline $\begin{array}{l}\text { Pre grazing forage mass ( } \mathrm{kg} \text { DM/ha) } \\
\text { Colmo }(\%) \\
\text { Stem }(\%)\end{array}$ & $41,7^{\mathrm{a}}$ & $41,6^{\mathrm{a}}$ & $40,8^{\mathrm{a}}$ & $43,4^{\mathrm{a}}$ & 41,8 & 19,3 & $\mathrm{P}>0,98$ \\
\hline $\begin{array}{l}\text { Folha }(\%) \\
\text { Leaf }(\%)\end{array}$ & $40,6^{\mathrm{a}}$ & $33,4^{\mathrm{ab}}$ & $34,5^{\mathrm{ab}}$ & $18,4^{\mathrm{b}}$ & 32,2 & 19,7 & $\mathrm{P}<0,01$ \\
\hline $\begin{array}{l}\text { Material morto }(\%) \\
\text { Dead material }(\%)\end{array}$ & $17,7^{\mathrm{b}}$ & $24,9^{\mathrm{ab}}$ & $24,7^{\mathrm{ab}}$ & $38,2^{\mathrm{a}}$ & 26,1 & 29,8 & $\mathrm{P}<0,02$ \\
\hline $\begin{array}{l}\text { Folha: colmo pré-pastejo } \\
\text { Leaf:stem ratio pre grazing }\end{array}$ & $1,08^{\mathrm{a}}$ & $0,85^{\mathrm{a}}$ & $0,91^{\mathrm{a}}$ & $0,60^{\mathrm{a}}$ & 0,88 & 37,7 & $\mathrm{P}>0,34$ \\
\hline $\begin{array}{l}\text { Resíduo (kg/MS/ha) } \\
\text { Residue (kg DM/ha) }\end{array}$ & $3333^{\mathrm{a}}$ & $2713^{a}$ & $2196^{\mathrm{a}}$ & $2672^{\mathrm{a}}$ & 2730 & 21,8 & $\mathrm{P}>0,23$ \\
\hline $\begin{array}{l}\text { Colmo }(\%) \\
\text { Stem }(\%)\end{array}$ & $58,6^{\mathrm{a}}$ & $53,3^{\mathrm{a}}$ & $61,9^{\mathrm{a}}$ & $53,8^{\mathrm{a}}$ & 57,0 & 12,2 & $\mathrm{P}>0,41$ \\
\hline $\begin{array}{l}\text { Folha }(\%) \\
\text { Leaf }(\%)\end{array}$ & $14,5^{\mathrm{a}}$ & $14,0^{\mathrm{a}}$ & $11,9^{\mathrm{a}}$ & $4,1^{\mathrm{a}}$ & 11,4 & 56,3 & $P>0,23$ \\
\hline $\begin{array}{l}\text { Material morto }(\%) \\
\text { Dead material }(\%)\end{array}$ & $26,9^{a}$ & $32,7^{\mathrm{a}}$ & $26,1^{\mathrm{a}}$ & $42,0^{\mathrm{a}}$ & 31,6 & 27,6 & $\mathrm{P}>0,15$ \\
\hline $\begin{array}{l}\text { Folha: colmo pré-pastejo } \\
\text { Leaf:stem ratio pre grazing }\end{array}$ & $0,27^{\mathrm{a}}$ & $0,30^{\mathrm{a}}$ & $0,19^{\mathrm{a}}$ & $0,10^{\mathrm{a}}$ & 0,22 & 61,0 & $P>0,32$ \\
\hline $\begin{array}{l}\text { Leaf:stem ratio pre grazing } \\
\text { Taxa de lotação (UA/ha) }{ }^{1} \\
\text { Stocking rate }(U A / h a)^{l}\end{array}$ & 3,68 & 2,23 & 3,84 & 2,42 & 3,04 & & \\
\hline
\end{tabular}

Médias seguidas por letras diferentes na linha diferem $(\mathrm{P}<0,05)$ pelo teste Tukey.

Means followed by different letters, within a row, are different $(P<.05)$ by Tukey test.

${ }^{1} \mathrm{~A}$ taxa de lotação não foi comparada estatisticamente. UA = unidade animal de $450 \mathrm{~kg}$.

1 The stocking rate was not statistically compared. UA = animal unit of $450 \mathrm{~kg}$.

* Nível de significância.

* Significant level. 
No mesmo local e com o mesmo manejo, no ano anterior, Rosseto (2000) encontrou média de massa de forragem inicial (pré-pastejo), por ciclo de pastejo, de $7.781 \mathrm{~kg}$ de MS/ha, suportando taxa de lotação média de 5,13 UA/ha no capim-elefante, resultados superiores ao obtido neste trabalho. Balsalobre (1996), trabalhando com capim-elefante, também encontrou resultados superiores para massa de forragem prépastejo, quando comparado com o presente trabalho.

Trabalhando com capim-Tanzânia, Cecato et al. (1996) encontraram produção de massa de forragem inicial superior à obtida neste trabalho, enquanto Santos et al. (1999), resultados mais próximos.

No capim-Tanzânia (Tabela 2), comparando o $1 \underline{0}$ e 4o ciclos de pastejo, foi observada diminuição significativa $(\mathrm{P}<0,01)$ na proporção de folhas de $55,7 \%$ para $17,2 \%$ e aumento significativo $(\mathrm{P}<0,04)$ na proporção de colmo e de material morto $(\mathrm{P}<0,01)$. Conseqüentemente, a relação folha: colmo foi sendo reduzida $(\mathrm{P}<0,01)$. Santos et al. (1999) também encontraram diminuição significativa da proporção folha: colmo, quando compararam o primeiro e o último ciclo de pastejo de um mesmo verão, em capim-Tanzânia adubado com $400 \mathrm{~kg}$ de $\mathrm{N}$ e ciclo de pastejo de 38 dias.

Folhas, colmos e material morto que desapareceram após o pastejo foram calculados como a diferença entre os valores encontrados na massa de forragem inicial e no resíduo (Figura 1).

Durante todo o período experimental, as pastagens de capim-elefante sofreram sucessivos ataques de cigarrinha (Deois flavopicta), o que prejudicou o desenvolvimento desta planta forrageira. Durante o 2o ciclo de pastejo, houve um ataque de lagartas (Mocis latipes) nas duas áreas estudadas, porém mais severo na área de capim-elefante que na de Tanzânia. Embora as duas áreas tenham sido pulverizadas com inseticida, o $2 \underline{\underline{o}}$ ciclo de pastejo do

Tabela 2 - Médias e coeficiente de variação (CV) da massa de forragem pré-pastejo, resíduo (pós-pastejo), porcentagem de colmo, folha, material morto, relação folha:colmo e taxa de lotação em capim-Tanzânia

Table 2 - Average and coefficient of variation (CV) of pre grazing forage mass, residue (after grazing), percentage of stem, leaf, dead material, leaf:stem relation and stoking rate in Tanzaniagrass

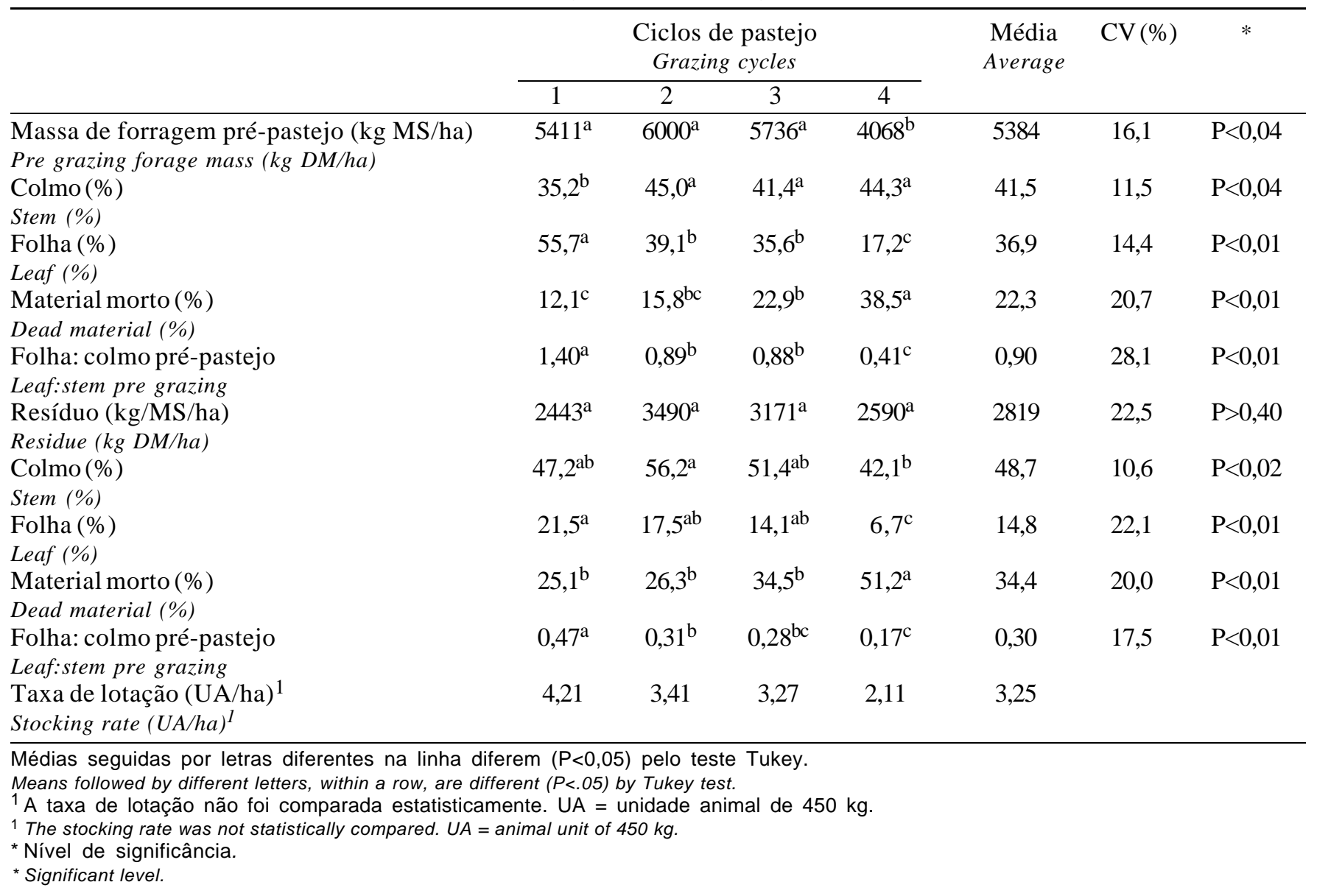

\section{R. Bras. Zootec., v.33, n.6, p.1616-1626, 2004}



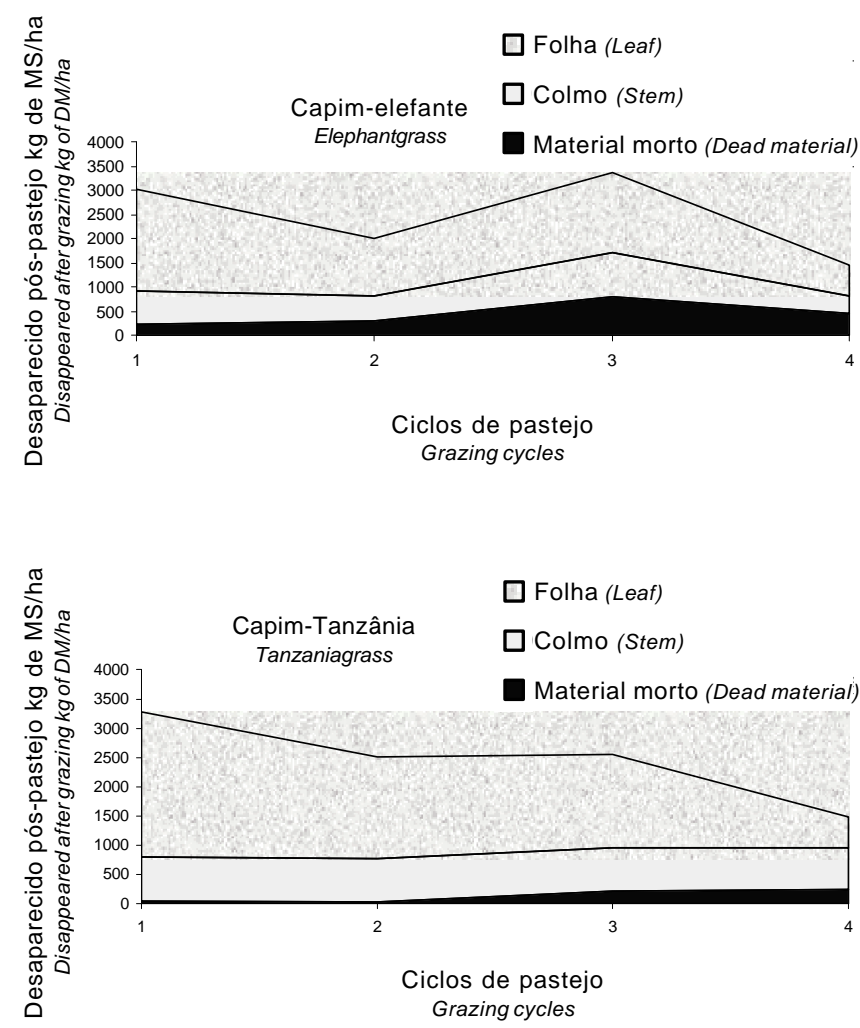

Figura 1 - Folha, colmo e material morto desaparecido pós-pastejo de capim-elefante e capimTanzânia, nos quatro ciclos de pastejo.

Figure 1 - Leaf, stem and dead material disappeared after grazing of elephantgrass and Tanzaniagrass, in the four grazing cycles.

capim-elefante foi muito prejudicado, com diminuição na quantidade de folhas. No 40 ciclo de pastejo, ambos os capins floresceram, apresentando drástica redução na proporção de folhas.

Os resultados das análises de PB e FDN para o capim-elefante podem ser observados na Tabela $3 \mathrm{e}$ para o capim-Tanzânia, na Tabela 4.

Nas amostras de capim-elefante, apesar de não ter sido observada diferença significativa, houve diferença numérica, com diminuição na PB e aumento da FDN da planta inteira no $2 \underline{\mathrm{o}}$ ciclo de pastejo, em relação ao $1 \underline{0}$ ciclo de pastejo. Em relação às folhas do capim-elefante, houve diferença significativa para PB e FDN no $2 \underline{o}$ ciclo de pastejo, em relação ao $1 \underline{0}$ ciclo, provavelmente em conseqüência do ataque de pragas que ocorreu nesse período.

Olivo et. al. (1992), trabalhando com pastagem de capim-elefante, encontraram média de $8,14 \%$ de
PB em amostras de pastagem de capim-elefante coletadas a $20 \mathrm{~cm}$ do solo, no período de novembro a abril, valor semelhante aos $8,4 \%$ de $\mathrm{PB}$ obtidos no presente trabalho.

Balsalobre (1996) encontrou média de 8,73\% de PB em folhas de capim-elefante. Ribeiro et al. (1999), em pastagens de capim-elefante anão, verificaram teor médio de PB nas folhas de 11,3\%, ambas inferiores à média obtida neste trabalho $(12,5 \%)$. Fonseca et al. (1998) encontraram 11,91\% de PB em lâminas foliares de capim-elefante, valores mais próximos à média deste trabalho.

Nos colmos, o teor médio de $6,9 \%$ para PB encontrado no presente trabalho foi similar ao resultado (6,8\%) observado por Ribeiro et al. (1999), trabalhando com capim-elefante anão, enquanto Balsalobre (1996) encontrou média menor (PB do colmo de 3,94\% em capim-elefante). Fonseca et al. (1998) também encontraram médias menores, entre 2,78 e $4,51 \%$ de PB em capim-elefante.

Os valores médios encontrados para FDN em capim-elefante, no presente trabalho, foram menores, tanto para folha $(65,0 \%)$ como para colmo $(70,8 \%)$, quando comparados aos valores citados por Balsalobre (1996), trabalhando com capim-elefante, e por Fonseca et al. (1998), médias entre 62,3 e 70,6\% de FDN para lâminas foliares de capim-elefante e entre 71,4 e $78,2 \%$ de FDN para colmo, em três anos de estudo.

Nas amostras do capim-Tanzânia, diminuição gradativa da PB e aumento gradativo da FDN da planta inteira foram observados, à medida que a estação das águas se aproximou do final, com diferença significativa entre o 1 o e o 40 ciclos de pastejo apenas para PB. O florescimento de ambos os capins Tanzânia e elefante ocorreu durante o $4^{\circ}$ ciclo de pastejo.

A média para PB nas folhas de capim-Tanzânia foi de $14,3 \%$, maior que as médias relatadas por Euclides (1995), de 12,0\% de PB no período das águas para esse capim, e Jank \& Costa (1990), de 12,5\% para PB. Para os colmos, no presente trabalho a média encontrada foi de $7,4 \%$, menor que a observada por Euclides (1995), de 10,1\% para PB.

No capim-Tanzânia, o aumento da proporção de colmo nos meses de abril e maio é inevitável, em decorrência da inflorescência. Segundo Corsi (1995), deve-se estar atento ao aumento da proporção de caule, que resulta em diminuição da digestibilidade das plantas forrageiras do gênero Panicum e, por esse motivo, deve-se escolher uma época mais adequada para seu uso. 
Na Figura 2, podem ser observadas as estimativas das quantidades de proteína bruta provenientes das folhas que desapareceram com o pastejo, em cada ciclo de pastejo, para cada espécie de capim.

Os resultados médios encontrados para concentração de N uréico no plasma sangüíneo (NUP) e produção de leite das vacas mestiças podem ser observados na Figura 3. As médias de NUP encontradas estão entre os valores 7 e $19 \mathrm{mg} / \mathrm{dL}$, considerados adequados para vacas em lactação (Butler, 1996, Hayes et al., 1996; Broderik \& Clayton, 1997). Não houve efeito do grau de sangue $(P>0,29)$ e da fase de lactação $(\mathrm{P}>0,76)$ na concentração de $\mathrm{N}$ uréico plasmático das vacas. Observou-se efeito significativo $(\mathrm{P}<0,046)$ da interação entre tipo de capim e ciclo de pastejo e, portanto, a análise

Tabela 3 - Médias e coeficientes de variação (CV) para proteína bruta (PB) e fibra em detergente neutro (FDN), na matéria seca, das amostras pré-pastejo e pós-pastejo (resíduo), em capim-elefante

Table 3 - Average and coefficient of variation (CV) of crude protein (CP) and neutral detergent fiber (NDF) in dry matter of samples before grazing and after grazing (residue) in elephantgrass

\begin{tabular}{|c|c|c|c|c|c|c|c|c|}
\hline & & \multicolumn{4}{|c|}{$\begin{array}{l}\text { Ciclos de pastejo } \\
\text { Grazing cycles }\end{array}$} & \multirow[t]{2}{*}{$\begin{array}{l}\text { Média } \\
\text { Average }\end{array}$} & \multirow[t]{2}{*}{$\mathrm{CV}(\%)$} & \multirow[t]{2}{*}{$*$} \\
\hline & & 1 & 2 & 3 & 4 & & & \\
\hline \multicolumn{9}{|c|}{$\begin{array}{c}\text { Pré-pastejo } \\
\text { Before grazing }\end{array}$} \\
\hline \multirow{2}{*}{$\begin{array}{l}\text { Planta inteira } \\
\text { Intact plant }\end{array}$} & PB \% & $9,8^{\mathrm{a}}$ & $7,8^{\mathrm{a}}$ & $8,9^{\mathrm{a}}$ & $6,3^{\mathrm{a}}$ & 8,4 & 20,9 & $\mathrm{P}<0,12$ \\
\hline & $\begin{array}{l}C P \% \\
\text { FDN \% } \\
N D F \%\end{array}$ & $76,2^{\mathrm{a}}$ & $81,8^{\mathrm{a}}$ & $77,0^{\mathrm{a}}$ & $79,7^{\mathrm{a}}$ & 78,5 & 3,6 & $\mathrm{P}<0,17$ \\
\hline \multirow{2}{*}{$\begin{array}{l}\text { Colmo } \\
\text { Stem }\end{array}$} & PB \% & $7,7^{\mathrm{a}}$ & $6,2^{\mathrm{b}}$ & $8,0^{\mathrm{a}}$ & $5,2^{\mathrm{b}}$ & 6,9 & 29,1 & $\mathrm{P}<0,01$ \\
\hline & $\begin{array}{l}C P \% \\
\text { FDN \% }\end{array}$ & $73,4^{\mathrm{b}}$ & $79,3^{\mathrm{a}}$ & $78,1^{\mathrm{ab}}$ & $78,2^{\mathrm{a}}$ & 77,1 & 3,6 & $\mathrm{P}<0,01$ \\
\hline \multirow[t]{2}{*}{$\begin{array}{l}\text { Folhas } \\
\text { Leaf }\end{array}$} & $\begin{array}{l}\mathrm{PB} \% \\
\mathrm{CP} \%\end{array}$ & $12,4^{\mathrm{a}}$ & $10,8^{b}$ & $15,3^{\mathrm{a}}$ & $11,2^{\mathrm{b}}$ & 12,5 & 10,7 & $\mathrm{P}<0,05$ \\
\hline & $\begin{array}{l}\text { FDN \% } \\
N D F \%\end{array}$ & $75,3^{\mathrm{b}}$ & $78,9^{\mathrm{a}}$ & $72,6^{\mathrm{b}}$ & $78,6^{\mathrm{a}}$ & 76,3 & 3,9 & $\mathrm{P}<0,01$ \\
\hline \multirow{2}{*}{$\begin{array}{l}\text { Material morto } \\
\text { Dead material }\end{array}$} & PB \% & $5,7^{\mathrm{a}}$ & $4,5^{\mathrm{a}}$ & $5,9^{\mathrm{a}}$ & $4,8^{\mathrm{a}}$ & 5,3 & 22,3 & $\mathrm{P}>0,13$ \\
\hline & $\begin{array}{c}C P \% \\
\text { FDN \% } \\
N D F \%\end{array}$ & $81,0^{\mathrm{b}}$ & $83,7^{\mathrm{a}}$ & $83,3^{\mathrm{a}}$ & $82,8^{\mathrm{ab}}$ & 82,6 & 3,5 & $\mathrm{P}<0,01$ \\
\hline \multicolumn{9}{|c|}{$\begin{array}{l}\text { Pós-pastejo } \\
\text { After grazing }\end{array}$} \\
\hline \multirow{2}{*}{$\begin{array}{l}\text { Resíduo } \\
\text { Residue }\end{array}$} & PB \% & $6,8^{\mathrm{a}}$ & $6,2^{\mathrm{a}}$ & $6,9^{\mathrm{a}}$ & $6,0^{\mathrm{a}}$ & 6,5 & 26,4 & $\mathrm{P}>0,61$ \\
\hline & $\begin{array}{c}C P \% \\
\text { FDN \% } \\
N D F \%\end{array}$ & $81,8^{a}$ & $78,2^{\mathrm{b}}$ & $77,5^{\mathrm{b}}$ & $82,7^{\mathrm{a}}$ & 80,2 & 3,1 & $\mathrm{P}<0,01$ \\
\hline \multirow[t]{2}{*}{$\begin{array}{l}\text { Colmo } \\
\text { Stem }\end{array}$} & $\begin{array}{l}\text { PB \% } \\
C P \%\end{array}$ & $7,4^{\mathrm{a}}$ & $5,3^{\mathrm{a}}$ & $6,3^{\mathrm{a}}$ & $5,2^{\mathrm{a}}$ & 6,2 & 23,3 & $\mathrm{P}>0,06$ \\
\hline & $\begin{array}{l}\text { FDN \% } \\
N D F \%\end{array}$ & $76,9^{\mathrm{b}}$ & $78,2^{\mathrm{ab}}$ & $76,9^{\mathrm{b}}$ & $81,3^{\mathrm{a}}$ & 78,2 & 4,5 & $\mathrm{P}<0,01$ \\
\hline \multirow{2}{*}{$\begin{array}{l}\text { Folha } \\
\text { Leaf }\end{array}$} & PB \% & $9,7^{\mathrm{b}}$ & $10,4^{\mathrm{ab}}$ & $13,2^{\mathrm{a}}$ & $11,9^{a b}$ & 11,2 & 16,3 & $\mathrm{P}<0,03$ \\
\hline & $\begin{array}{l}C P \% \\
\text { FDN \% } \\
N D F \%\end{array}$ & $79,8^{\mathrm{a}}$ & $73,5^{\mathrm{bc}}$ & $69,7^{\mathrm{c}}$ & $76,0^{\mathrm{ab}}$ & 75,2 & 5,4 & $\mathrm{P}<0,01$ \\
\hline \multirow{2}{*}{$\begin{array}{l}\text { Material morto } \\
\text { Dead material }\end{array}$} & $\mathrm{PB} \%$ & $6,2^{\mathrm{a}}$ & $4,7^{\mathrm{a}}$ & $6,2^{\mathrm{a}}$ & $6,1^{\mathrm{a}}$ & 5,8 & 21,6 & $\mathrm{P}>0,06$ \\
\hline & $\begin{array}{c}C P \% \\
\text { FDN \% } \\
N D F \%\end{array}$ & $83,2^{\mathrm{a}}$ & $82,6^{\mathrm{a}}$ & $80,8^{\mathrm{a}}$ & $82,4^{\mathrm{a}}$ & 82,3 & 3,4 & $\mathrm{P}>0,09$ \\
\hline
\end{tabular}

Médias seguidas por letras diferentes na linha diferem $(P<0,05)$ pelo teste Tukey.

Means followed by different letters, within a row, are different $(P<.05)$ by Tukey test.

* Nível de significância.

* Significant level. 
estatística para NUP foi feita a partir do desdobramento das duas fontes de variação.

Comparando-se as vacas mantidas no capimelefante e no capim-Tanzânia, a concentração de N uréico no plasma sangüíneo (NUP) não diferiu no $1 \stackrel{0}{\circ}$ ciclo de pastejo, mas foi significativamente menor nas vacas mantidas no capim-elefante no $2 \stackrel{\circ}{\circ}(\mathrm{P}<0,01)$ e 3 o $(P<0,04)$ ciclos de pastejo, e significativamente maior $(\mathrm{P}<0,01)$ no 40 ciclo de pastejo.

Os menores valores encontrados para uréia plasmática foram observados quando ocorreram as menores proporções de folhas disponíveis, ou seja, no $2 \underline{0}$ e $4 \underline{\mathrm{o}}$ ciclos de pastejo no capim-elefante e no $4 \underline{\mathrm{o}}$ ciclo de pastejo, no capim-Tanzânia.

Com exceção do 40 ciclo de pastejo, os valores encontrados para uréia plasmática foram maiores

Tabela 4 - Médias e coeficiente de variação (CV) para proteína bruta (PB) e fibra em detergente neutro (FDN), na matéria seca, das amostras pré-pastejo e pós-pastejo (resíduo) em capim-Tanzânia

Table 4 - Average and coefficient of variation (CV) of crude protein (CP) and neutral detergent fiber (NDF) in dry matter of samples before grazing and after grazing (residue) in Tanzaniagrass

\begin{tabular}{|c|c|c|c|c|c|c|c|c|}
\hline & & \multicolumn{4}{|c|}{$\begin{array}{l}\text { Ciclos de pastejo } \\
\text { Grazing cycles }\end{array}$} & \multirow[t]{2}{*}{$\begin{array}{l}\text { Média } \\
\text { Average }\end{array}$} & \multirow[t]{2}{*}{ CV $(\%)$} & \multirow[t]{2}{*}{$*$} \\
\hline & & 1 & 2 & 3 & 4 & & & \\
\hline \multicolumn{9}{|c|}{$\begin{array}{c}\text { Pré-pastejo } \\
\text { Before grazing }\end{array}$} \\
\hline \multirow{2}{*}{$\begin{array}{l}\text { Planta inteira } \\
\text { Intact plant }\end{array}$} & PB \% & $10,5^{\mathrm{a}}$ & $9,5^{\mathrm{ab}}$ & $9,4^{\mathrm{ab}}$ & $7,8^{b}$ & 9,3 & 15,6 & $\mathrm{P}<0,02$ \\
\hline & $\begin{array}{c}C P \% \\
\text { FDN \% } \\
N D F \%\end{array}$ & $79,2^{\mathrm{a}}$ & $81,2^{\mathrm{a}}$ & $81,9^{\mathrm{a}}$ & $84,1^{\mathrm{a}}$ & 81,6 & 4,1 & $P>0,28$ \\
\hline \multirow{2}{*}{$\begin{array}{l}\text { Colmo } \\
\text { Stem }\end{array}$} & PB \% & $7,4^{\mathrm{a}}$ & $7,6^{\mathrm{a}}$ & $7,6^{\mathrm{a}}$ & $7,0^{\mathrm{a}}$ & 7,4 & 17,5 & $P>0,58$ \\
\hline & $\begin{array}{c}C P \% \\
\text { FDN \% } \\
N D F \%\end{array}$ & $82,1^{\mathrm{a}}$ & $82,5^{\mathrm{a}}$ & $82,7^{\mathrm{a}}$ & $82,2^{\mathrm{a}}$ & 82,4 & 4,3 & $P>0,89$ \\
\hline \multirow{2}{*}{$\begin{array}{l}\text { Folhas } \\
\text { Leaf }\end{array}$} & PB \% & $13,6^{\mathrm{a}}$ & $14,6^{\mathrm{a}}$ & $15,1^{\mathrm{a}}$ & $13,7^{\mathrm{a}}$ & 14,3 & 11,9 & $P>0,22$ \\
\hline & $\begin{array}{l}\text { FDN \% } \\
N D F \%\end{array}$ & $80,7^{\mathrm{a}}$ & $79,3^{\mathrm{b}}$ & $81,0^{\mathrm{a}}$ & $80,8^{\mathrm{a}}$ & 80,4 & 5,4 & $\mathrm{P}<0,01$ \\
\hline \multirow{2}{*}{$\begin{array}{l}\text { Material morto } \\
\text { Dead material }\end{array}$} & PB \% & $7,1^{\mathrm{a}}$ & $6,9^{\mathrm{a}}$ & $5,7^{b}$ & $5,6^{b}$ & 6,3 & 13,7 & $\mathrm{P}<0,01$ \\
\hline & $\begin{array}{l}\text { FDN \% } \\
N D F \%\end{array}$ & $81,7^{c}$ & $81,9^{b c}$ & $84,5^{\mathrm{a}}$ & $83,5^{\mathrm{a}}$ & 82,9 & 2,9 & $\mathrm{P}<0,01$ \\
\hline \multicolumn{9}{|c|}{$\begin{array}{l}\text { Pós-pastejo } \\
\text { After grazing }\end{array}$} \\
\hline \multirow{2}{*}{$\begin{array}{l}\text { Resíduo } \\
\text { Residue }\end{array}$} & $\begin{array}{l}\text { PB \% } \\
C P \%\end{array}$ & $8,1^{\mathrm{a}}$ & $7,9^{\mathrm{a}}$ & $7,5^{\mathrm{a}}$ & $7,0^{\mathrm{a}}$ & 7,6 & 12,6 & $\mathrm{P}>0,17$ \\
\hline & $\begin{array}{l}\text { FDN \% } \\
N D F \%\end{array}$ & $79,3^{b}$ & $81,2^{\mathrm{ab}}$ & $82,9^{\mathrm{a}}$ & $82,3^{\mathrm{a}}$ & 81,6 & 3,2 & $\mathrm{P}<0,01$ \\
\hline \multirow{2}{*}{$\begin{array}{l}\text { Colmo } \\
\text { Stem }\end{array}$} & PB \% & $7,2^{\mathrm{a}}$ & $7,5^{\mathrm{a}}$ & $7,9^{\mathrm{a}}$ & $8,5^{\mathrm{a}}$ & 7,8 & 22,8 & $P>0,18$ \\
\hline & $\begin{array}{c}C P \% \\
\text { FDN \% } \\
N D F \%\end{array}$ & $81,1^{\mathrm{a}}$ & $83,5^{\mathrm{a}}$ & $83,3^{\mathrm{a}}$ & $81,4^{\mathrm{a}}$ & 82,2 & 3,1 & $P>0,12$ \\
\hline \multirow[t]{2}{*}{$\begin{array}{l}\text { Folha } \\
\text { Leaf }\end{array}$} & $\begin{array}{l}\mathrm{PB} \% \\
\mathrm{CP} \%\end{array}$ & $10,8^{\mathrm{a}}$ & $11,8^{\mathrm{a}}$ & $11,7^{\mathrm{a}}$ & $11,4^{\mathrm{a}}$ & 11,4 & 18,2 & $P>0,40$ \\
\hline & $\begin{array}{l}\text { FDN \% } \\
N D F \%\end{array}$ & $79,6^{\mathrm{a}}$ & $79,9^{\mathrm{a}}$ & $79,8^{\mathrm{a}}$ & $80,1^{\mathrm{a}}$ & 79,8 & 3,6 & $P>0,41$ \\
\hline \multirow{2}{*}{$\begin{array}{l}\text { Material morto } \\
\text { Dead material }\end{array}$} & PB \% & $7,5^{\mathrm{a}}$ & $7,11^{\mathrm{ab}}$ & $5,7^{\mathrm{b}}$ & $6,1^{\mathrm{ab}}$ & 6,6 & 15,5 & $\mathrm{P}<0,02$ \\
\hline & $\begin{array}{c}C P \% \\
\text { FDN \% } \\
N D F \%\end{array}$ & $82,3 b$ & $85,5^{\mathrm{a}}$ & $84,3^{\mathrm{ab}}$ & $84,1^{\mathrm{ab}}$ & 83,9 & 2,5 & $\mathrm{P}<0,03$ \\
\hline
\end{tabular}

Médias seguidas por letras diferentes na linha diferem $(\mathrm{P}<0,05)$ pelo teste Tukey.

Means followed by different letters, within a row, are different $(P<.05)$ by Tukey test.

* Nível de significância.

* Significant level.

R. Bras. Zootec., v.33, n.6, p.1616-1626, 2004 


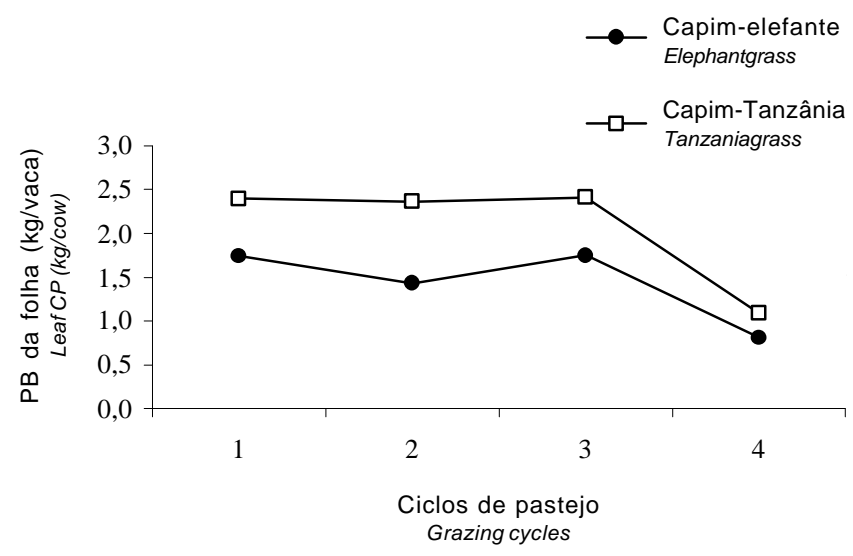

Figura 2 - Quantidade estimada de proteína bruta (PB) proveniente da folha, no capim-elefante e capim-Tanzânia, nos quatro ciclos de pastejo

Figure 2 - Amount estimates for crude protein (CP) from leaf, of elephantgrass and Tanzania grass, in four grazing cycles

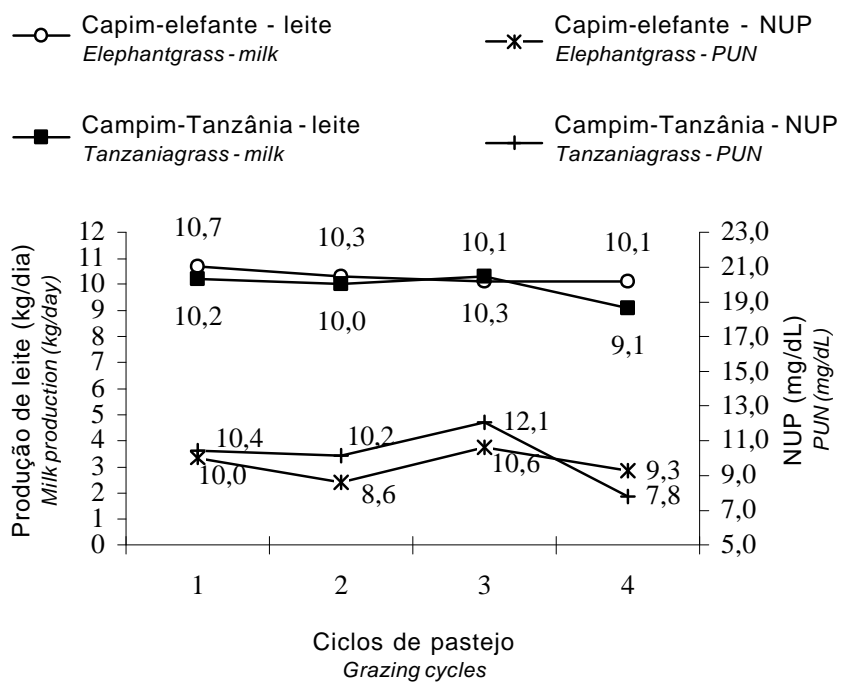

Figura 3 - Média diária da produção de leite e do nitrogênio uréico plasmático (NUP) do sangue de vacas leiteiras mestiças em mantidas em capim-elefante e capim-Tanzânia.

Figure 3 - Daily means of milk production and plasma urea nitrogen (PUN) of blood from crossbred dairy cows kept in elephantgrass and Tanzaniagrass.

valores semelhantes aos obtidos no presente trabalho.

A média da produção de leite foi $10,3 \mathrm{~kg} /$ dia para as vacas mantidas no capim-elefante e $10,0 \mathrm{~kg} / \mathrm{dia}$ para as vacas no capim-Tanzânia. Houve efeito significativo do grau de sangue $(\mathrm{P}<0,046)$ e da fase da lactação $(\mathrm{P}<0,01)$ na produção de leite. Não houve efeito significativo do capim $(\mathrm{P}>0,51)$ ou do ciclo de pastejo $(\mathrm{P}>0,29)$ na produção de leite e também nenhum efeito das interações. Foi observada queda na produção de leite das vacas mantidas no capimTanzânia no 4으 ciclo de pastejo, o que coincide com os níveis mais baixos de uréia no plasma sanguiíneo destas vacas (Figura 3). Os valores observados para produção de leite são similares aos relatados por Lucci et al. (1969, 1972) e Veloso \& Freitas (1973), mas inferiores ao valor de 11,4 kg de leite/vaca/dia observado por Aroeira et al. (1999), com vacas mantidas em capim-elefante.

As vacas foram acompanhadas por dois anos e não apresentaram problemas reprodutivos sérios. $\mathrm{O}$ intervalo médio de partos foi de 445 e 425 dias das vacas mantidas no capim-elefante e no capimTanzânia, respectivamente, ou seja, índice de fertilidade de $82 \%$ para as vacas do capim-elefante e $86 \%$ para as vacas do capim-Tanzânia. 


\section{Conclusões}

Quanto mais próximo do final da estação das águas, menor será a proporção de folhas nas pastagens de capim-elefante e capim-Tanzânia, inclusive com diminuição da proteína bruta das pastagens e dos níveis de nitrogênio uréico plasmático das vacas.

\section{Literatura Citada}

AROEIRA, L.J.M.; LOPES, F.C.F. ; DERESZ, F. et al. Pasture availability and dry matter intake of lactating crossbres cows grazing elefphant grass (Pennisetum purpureum Schum.). Animal Feed Science and Technology, v.78, n.2, p.313324, 1999.

BALSALOBRE, A.A.M. Desempenho de vacas em lactação sob pastejo rotacionado em capim-elefante. Piracicaba: Escola Superior de Agricultura Luiz de Queiroz, 1996. 127p. Dissertação (Mestrado em Agronomia) - Escola Superior de Agricultura Luiz de Queiroz, 1996.

BRODERIK, A.G.; CLAYTON, M.K. A statistical evaluation of animal and nutrition factors influencing concentrations of milk urea nitrogen. Journal of Dairy Science, v.80, n.11, p.2964-2971, 1997.

BUTLER, W.R. Symposium: optimizing protein nutrition for reproduction and lactation. Journal of Dairy Science, v.81, n.9, p.2533-2539, 1998.

BUTLER, W.R.; CALAMAN, J.J.; BEAM, S.W. Plasma and milk urea nitrogen in relation to pregnancy rate in lactating dairy cattle. Journal of Animal Science, v.74, n.4, p.858-865, 1996.

CECATO, U.; MARCO, A.A.F.B.; SAKAGUTI, E.S. et al. Avaliação de cultivares de Panicum maximum Jacq. In: REUNIÃO ANUAL DA SOCIEDADE BRASILEIRA DE ZOOTECNIA, 34., Fortaleza, 1996. Anais... Fortaleza: Sociedade Brasileira de Zootecnia, 1996. p.403-406

CORSI, M. Manejo de plantas forrageiras do gênero Panicum. In: PEIXOTO, A.M.; MOURA, J.C.; FARIA, V.P. (Eds.) Plantas forrageiras de pastagens. Piracicaba: Fundação de Estudos Agrários Luiz de Queiroz, 1995. p.57-77.

CÓSER, A.C.; MARTINS, C.E.; FONSECA, D.M.F. et al. Efeitos de diferentes períodos de ocupação da pastagem de capim-elefante sobre a produção de leite. Pesquisa Agropecuária Brasileira, v.34, n.5, p.861-866, 1999.

DAVISON, T.M.; COWAN, R.T.; SHEPHERD, R.K. et al. Milk production from cows grazing on tropical grass pastures. 1 . Effects of stocking rate and level of nitrogen fertilizer on the pasture and diet. Australian Journal of Experimental Agriculture, v.25 n.3, p.505-214, 1985a.

DAVISON, T.M.; COWAN, R.T.; SHEPHERD, R.K. et al. Milk production from cows grazing on tropical grass pastures. 2 . Effects of stocking rate and level of nitrogen on milk yields and pasture-milk relationship. Australian Journal of Experimental Agriculture, v.25 n.3, p. 515-223, 1985b.

DERESZ, F.; MOZZER, O.L. Produção de leite em pastagem de capim-elefante. In: SIMPÓSIO SOBRE CAPIMELEFANTE, 1990, Coronel Pacheco. Anais... Coronel Pacheco: EMBRAPA- CNPGL, 1990. p.155-72.

EUCLIDES, V. P. B. Valor alimentício de espécies forrageiras do Gênero Panicum. In: SIMPÓSIO SOBRE MANEJO DE PASTAGEM, 12., 1995, Piracicaba. Anais... Piracicaba:
Fundação de Estudos Agrários Luiz de Queiroz, 1995. p.245-276.

FONSECA, D.M.; SALGADO, L.T.; QUEIROZ, D.S. et al. Produção de leite em pastagem de capim-elefante sob diferentes períodos de ocupação dos piquetes. Revista Brasileira de Zootecnia, v.27, n.5, p.848-856, 1998.

HAYES, D.P.; PFEIFFER, D.U.; WILLIMSON, N.B. Effect of intraruminal monensin capsules on reproductive performance and milk production of dairy cows fed pasture Journal of Dairy Science, v.79, n.5, p.1000-1008, 1996.

JANK, L.; COSTA, J. C. G. Avaliação, seleção e lançamentos de novas cultivares de gramíneas da espécie Panicum maximum. In: ENCONTRO SOBRE PRODUÇAO DE SEMENTES DE PLANTAS FORRAGEIRAS, 4.,1990, São José do Rio Preto. Anais... São José do Rio Preto: Associação Paulista de Produtores de Sementes e Mudas, 1990. p.1-15.

LUCCI, C.S.; ROCHA, G.L.; KALIL, E.B. Produção de leite em pastos de napier (Pennisetum purpureum) II. Boletim de Indústria Animal, v.26, n. único, p.165-172, 1969.

LUCCI, C.S.; ROCHA, G.L.; FREITAS, E.A.N. Produção de leite em regime exclusivo de pastagens de capim fino e napier. Boletim de Indústria Animal, v.29, n.1, p.45-51, 1972.

OLIVO, C. J.; MOREIRA, J. C.; BARRETO, I. L. et al. Utilização de pastagens de capim-elefante e capim-setária como base da alimentação de vacas em lactação, durante o verão. Revista da Sociedade Brasileira de Zootecnia, v.21, n.3, p.347352,1992

RIBEIRO, K.G.; GOMIDE, J.A.; PACIULLO, D.S.C. Adubação nitrogenada co capim-elefante cv. Mott. 2. Valor nutritivo ao atingir 80 e $120 \mathrm{~cm}$ de altura. Revista Brasileira de Zootecnia, v.28, n.6, p.1194-1202, 1999.

ROSSETO, F.A.A. Desempenho agronômico de plantas forrageiras em dois sistemas de produção de leite baseados no uso de pastagens de capim elefante cv. Guaçu (Pennisetum purpureum) e capim-Tanzânia (Panicum maximum). Piracicaba: Escola Superior de Agricultura Luiz de Queiroz, 2000. 221p. Dissertação (Mestrado em Agronomia) - Escola Superior de Agricultura Luiz de Queiroz, 2000.

ROWLANDS, G.J.; LITTLE, W.; KITCHENHAM, B.A. Relationships between blood composition and fertility in dairy cows - a fields study. Journal of Dairy Research, v.44, n.1, p.1-7, 1977.

RUAS, J.R.M.; TORRES, C.A.A.; BORGES, L.E. et al. Efeito da suplementação protéica a pasto sobre eficiência reprodutiva e concentração sangüínea de colesterol, glicose e uréia em vacas Nelore. Revista Brasileira de Zootecnia, v.29, n. 6 , p. 2043-2050, 2000.

RUEEG, P.L.; GOODGER, W.J.; HOLMBERG, C.A. et al. Relation among body condition score, serum urea nitrogen and cholesterol concentrations, and reproductive performance in high-producing Holstein dairy cows in early lactation. American Journal of Veterinary Research, v.53, n.1, p.10-14, 1992.

SANTOS, P.M.; CORSI, M.; BALSALOBRE, M.A.A. et al. Efeito da frequência de pastejo e de época do ano sobre a produção e a qualidade em Panicum maximum cv. Tanzânia e Mombaça. Revista da Sociedade Brasileira de Zootecnia, v.28, n.2, p.244-249, 1999.

STATISTICAL ANALYSES SYSTEM - SAS. User'g guide: statistics. Cary: 1996. 965p.

SEARCY, R.L; REARDON, J.E.; FOREMAN, J.A. A new photometric method for serum urea nitrogen determination.

R. Bras. Zootec., v.33, n.6, p.1616-1626, 2004 
American Journal Medical Technology, v.33, n.1, p.1520, 1967.

SILVA, D.J. Análise de alimentos (métodos químicos e biológicos). 2.ed. Viçosa, MG: Universidade Federal de Viçosa, 1990. 165p.

TABACCO, A.; MEIATTINI, F.; MODA, E. et al. Simplifies enzymic colorimetric serum urea nitrogen determination. Clinical Chemistry, v.25, n.2, p.335-336, 1979.

VELOSO, L.; FREITAS, E.A.N. Produção de leite com vacas manejadas em pastos de gramíneas e pasto consorciados (gramíneas + leguminosas). Zootecnia, v.11, n.3, p.177-182, 1973 .

Recebido em: 25/06/02

Aceito em: 23/03/04 